\title{
SOFT TISSUE MYOEPITHELIAL CELL CARCINOMA
}

Singapore Med J 2016; 57(3): 166-167 doi: 10.11622/smedj.2016058

Dear Sir,

Myoepithelial cell carcinoma, first described by Stromeyer et al in 1975, is defined as a malignant carcinoma that primarily arises from the parotid gland; ${ }^{(1)}$ it may also arise from the mammary glands. In 1991, myoepithelial cell carcinoma was added to the second edition of the World Health Organization's classification of malignant salivary gland tumours. ${ }^{(2)}$ Soft tissue myoepithelial cell carcinoma (STMC) is rare compared to its counterparts arising from the salivary glands.

We herein describe the case of a 39-year-old man who was referred to Singapore General Hospital, Singapore, for swelling of the left thigh that was initially diagnosed as extraosseous chondrosarcoma. However, repeat biopsy results indicated the diagnosis of STMC. The patient had undergone two cycles of neoadjuvant chemotherapy. Subsequent repeat magnetic resonance imaging showed that the tumour, which arose from the vastus medialis, had increased in size from approximately $20.0 \mathrm{~cm} \times 18.8 \mathrm{~cm} \times 27.3 \mathrm{~cm}$ to about $23.2 \mathrm{~cm} \times 20.1 \mathrm{~cm} \times 32.9 \mathrm{~cm}$. Surgical resection options were discussed, but the patient declined surgery.

STMC is rarely reported compared to carcinoma of the parotid gland. Patients who were diagnosed with STMC ranged from 3-83 years of age, with a mean age of 40 years and a slight male predilection. ${ }^{(3)}$ Nearly two-thirds of reported cases were for tumours arising from the extremities (38\% lower and 27\% upper extremity); the remainder involved the head and the neck regions (16\%), trunk (13\%), and visceral soft tissue (6\%). ${ }^{(4)}$ Approximately $60 \%$ of these tumours are subcutaneous in origin and $40 \%$ occur in deep soft tissue (i.e. intramuscular or subfascial). ${ }^{(4)}$

In our patient, we experienced difficulty in interpreting the histological diagnosis. This is not uncommon as, due to histological polymorphism, STMC poses different challenges. Several entities share similar characteristics with STMC. Hence, immunohistochemistry investigation plays a vital role in differentiating this type of tumour. The neoplastic myoepithelial cells express the epithelial markers AE1/AE3 (90\%) and EMA (60\%), and myoepithelial markers S-100 protein (89\%), calponin (87\%), glial fibrillary acidic protein (46\%) and smooth muscle actin (36\%). ${ }^{(5)}$

Regarding the genetic study of myoepithelial cell carcinoma, the study by Antonescu et al, which included 66 cases, showed that the EWS RNA-Binding Protein 1 (EWSR1) gene rearrangement was a common event in myoepithelial tumours arising outside of salivary glands, as found in $45 \%$ of cases. ${ }^{(6)}$ The EWSR 1 gene is located on chromosome band $22 \mathrm{q} 12$ and encodes a promoterspecific transactivator. ${ }^{(7)}$ EWSR1 gene rearrangement is also associated with several neoplasms such as Ewing's sarcoma, clear cell sarcoma, myxoid liposarcoma and extraskeletal myxoid chondrosarcoma. ${ }^{(6)}$ However, a study by Rekhi et al ${ }^{(7)}$ reported that only $50 \%$ of STMC cases expressed EWSR1 gene rearrangement; similarly, our patient did not exhibit EWSR1 gene rearrangement. This indicated that EWSR1 gene rearrangement may not necessarily present in general cases of STMC. Another study by Aparicio et al showed that a patient diagnosed with EWSR1-negative subsequently passed away due to multiple metastasis, ${ }^{(8)}$ suggesting a poor prognosis and the need for close follow-up.

Complete surgical resection is recommended for treatment of myoepithelial cell carcinoma. As our patient declined surgery, he only received chemotherapy, which failed to control the tumour locally. A recent study has reported positive clinical outcomes through the use of a treatment strategy involving a combination of aggressive local control, chemotherapy and radiotherapy. ${ }^{(9)}$ However, as the study mainly involved paediatric patients and was limited by its small size, further long-term patient follow-up is required. Two studies reported a $42 \%$ risk of local recurrence of the tumour and that a further $32 \%-52 \%$ had metastasised. ${ }^{(3,10)}$ This indicates that myoepithelial cell carcinoma can have an aggressive clinical course. Common reported sites of metastasis include the lungs, bone, lymph nodes and soft tissue. ${ }^{(10)}$ Even benign myoepithelioma tumours have a reported $20 \%$ risk of local recurrence. ${ }^{(3)}$

In conclusion, due to the rare nature of STMC, it remains a diagnostic challenge. However, the implementation of immunochemistry and genetic typing as diagnostic tools will help to accurately differentiate STMC from other tumours and, in turn, improve prognosis. As there is currently no general consensus on the management of STMC, a combination strategy may be the key to the treatment of this particular tumour.

Yours sincerely,

Mun Chun Lai ${ }^{1}$, Mann Hong $\underline{T a n}^{1}$

${ }^{1}$ Department of Orthopaedic Surgery, Singapore General Hospital, Singapore. cmunchun2001@yahoo.com

\section{References}

1. Stromeyer FW, Haggitt RC, Nelson JF, Hardman JM. Myoepithelioma of minor salivary gland origin. Light and electron microscopical study. Arch Pathol 1975; 99:242-5.

2. Seifert G, Sobin LH. The World Health Organization's Histological Classification of Salivary Gland Tumors. A commentary on the second edition. Cancer 1992; 70:379-85.

3. Hornick JL, Fletcher CD. Myoepithelial tumors of soft tissue: a clinicopathologic and immunohistochemical study of 101 cases with evaluation of prognostic parameters. Am J Surg Pathol 2003; 27:1183-96. 
4. Gleason BC, Hornick JL. Myoepithelial tumours of skin and soft tissue: an update. Diagn Histopathol 2008; 14:552-62.

5. Lee JR, Georgi DE, Wang BY. Malignant myoepithelial tumor of soft tissue: a report of two cases of the lower extremity and a review of the literature. Ann Diagn Pathol 2007; 11:190-8.

6. Antonescu CR, Zhang L, Chang NE, et al. EWSR1-POU5F1 fusion in soft tissue myoepithelial tumors. A molecular analysis of sixty-six cases, including soft tissue, bone, and visceral lesions, showing common involvement of the EWSR1 gene. Genes Chromosomes Cancer 2010; 49:1114-24.

7. Rekhi B, Sable M, Jambhekar NA. Histopathological, immunohistochemical and molecular spectrum of myoepithelial tumours of soft tissues. Virchows Arch 2012; 461:687-97.

8. Aparicio MA, López-Barea F, Cruz JJ, et al. Soft tissue myoepithelial carcinoma without EWSR1 gene rearrangement and poor outcome. A case report. Rev Esp Patol 2012; 45:58-63.

9. Bisogno G, Tagarelli A, Schiavetti A, et al. Myoepithelial carcinoma treatment in children: a report from the TREP project. Pediatr Blood Cancer 2014; 61:643-6.

10. Jo VY, Fletcher CD. Myoepithelial neoplasms of soft tissue: an updated review of the clinicopathologic, immunophenotypic, and genetic features. Head Neck Pathol 2015; 9:32-8. 